\title{
Ethics, Equality and Inclusion for Students with a Chronic Health Condition
}

\author{
Tony Potas ${ }^{1}$ and Anthony Jones ${ }^{2}$ \\ 1 Royal Children's Hospital Education Institute, Melbourne, Australia \\ tony.potas@rch.org.au, \\ WWW home page: http://www.rch.org.au/edinst/ \\ 2 ICT in Education and Research, Faculty of Education,University of \\ Melbourne, Australia \\ a.jones@unimelb.edu.au, \\ WWW home page: http://www.edfac.unimelb.edu.au/cgi- \\ bin/public/staff_profile.cgi?id=7001
}

\begin{abstract}
Students with a chronic disease are often overlooked by education systems. The World Health Organization (WHO) characterizes chronic diseases conditions that "are permanent, leave residual disability, are caused by nonreversible pathological alteration, require special training of the patient for rehabilitation or may require a long period of supervision, observation and care" [1]. Research data indicates that in many cases these students are at risk of dropping out of school. In order to redress the imbalance of access and equity for students with a chronic health condition, the Royal Children's Hospital Education Institute in Melbourne, Australia, has developed programs that based on an educational model designed to empower schools to support this cohort of students. In this paper the implementation and evaluation of two projects developed in response educational needs of students who are absent from school for extended periods because of chronic illness are presented. While both projects have been successfully implemented, a new research component in the second project has only recently commenced.
\end{abstract}

\section{Introduction}

The Royal Children's Hospital Education Institute (the Institute) was founded in 1998 replacing the previous Special School that was regulated by the Victorian state Department of Education and Early Childhood Development (DEECD). Historically teachers within the Special School setting at hospitals provided small-group and face- to-face bedside teaching for students admitted as inpatients. 
The need for in-house teachers was seen as critical to students' academic progress as their stay in hospital could be lengthy. Over the past decade the length of stay in hospital for children and young people has reduced [1] due in part to medical technology, community based health support systems and home care. In 2007 the Institute's database indicated that 1528 students required educational support, with $1146(75 \%)$ spending less than 3 weeks in hospital.

These briefer stays in hospital caused the Institute to redefine its support role, employing teachers and health professionals as Education Advisors to liaise with the student's school to ensure educational and social continuity. This empowering of schools involved providing teachers, school coordinators, students and their peers with relevant information, communications tools, and pathways that promoted ongoing teaching and learning despite student isolation and medical needs. This approach enables schools to comply with state and federal anti-discrimination and equity legislation.

Historically the Education Institute has used a range of ICTs to support the connection between students and their schools, for example trialing Blackberries, and video phones, setting up a student portal, accessing the Technical and Further Education virtual campus, setting up a web server using Manhattan as open source virtual classroom environment, and recently purchasing and installing Adobe Connect video conferencing software. But the sustainability of the majority of these communications systems has been problematic. Cost is always a factor in determining which system provides the best outcomes for students and schools.

Schools are slow to embrace this type of technology, due in part to the range of communications systems used by schools all having different interfaces and functionality requirements. Security is always an issue, with firewalls configured to block connections with services outside the school domain. The lack of school staff with the expertise to maximize the potential of new and emerging technologies and the take-up is further exacerbated by lack of training programs at the school level.

In supporting the need for effective ongoing communications with key stakeholders, the Institute uses new and emerging ICT and related research to inform best practice in the development of models that assist schools minimize the disconnection of students with chronic health conditions. Using such technologies is part of the Institute's accountability framework, and two projects that make different uses of ICT to support students who are absent from school are reported here.

\section{Education Advisory Service (EAS)}

The EAS is in its ninth year of operation. Funding for the service is provided by DEECD through the provision of a strategic contract with the Student Wellbeing branch. The EAS brings together and disseminates education and health knowledge to provide the best possible outcomes for students with a chronic health condition. To achieve this purpose the service is designed to empower schools by enhancing or building their capacity to support this cohort of students.

Information and communications technologies are one of many empowerment tools used by the service to connect students to their curriculum and peer-group. 
Research reported by the Commonwealth Department of Education, Science and Training [2] about the capacity of ICT to improve learning and teaching shows that it can play a key role in the complex task of better engaging students in their learning process. There is ample literature indicating that the use of on-line web-based virtual classrooms has surged ahead in the last ten years. This type of technology is utilized by the service to connect students to their school's curriculum and their peer group.

In 2006 an evaluation of the service was conducted by The University of Melbourne, Centre for Program Evaluation. The evaluation report [3] included feedback from the following stakeholder domains; the home, the school and the hospital. A section of the report noted that the use of information and communications technologies to maintain real time contact with students with chronic health conditions seems, at this stage, to be under-utilised by schools. ICT such as video conferencing and the RCH Education Institute's virtual classroom have not been widely taken up by schools, as options for supporting students with chronic health conditions in maintaining connections with their school activities and peers during periods of absence [3].

\subsection{Participants}

Students referred to the service are patients of the $\mathrm{RCH}$, and enrolled in primary or secondary level at a government, Catholic or independent school, and have a health condition that will have or is having a significant impact on their education. Education Advisors assigned to the service attend multidisciplinary team meetings for a wide range of diagnostic groups at $\mathrm{RCH}$ that refer to the service. Working with health professionals in this context assists the Education Advisor to establish the education and social implications associated with the student's medical treatment.

Both education and health systems place the student/patient and the family at the centre of care, a model that embraces collaboration, empowerment and education. This supports the principles of inclusion and individualized education for all students as referred to in the Blueprint for government schools [4].

The key contact person at the student's school depends in part on the student's level of schooling, primary or secondary. In a primary setting the classroom teacher is generally the key contact with additional support from an Assistant Principal usually assigned a welfare role in the school. In a secondary setting the key contact may be a Year Level Coordinator or a Welfare Coordinator or an Integration Coordinator.

\subsection{Method}

One part of the evaluation report [3] was a literature review whose initial focus was to identify best practice models that support the educational and social needs of students with a chronic health condition. It was found that documented examples of such models in Australian or international literature was limited. However, the review indicated that a large number of studies articulate stakeholder concerns about the educational and social support for students with a chronic health. 
Part of the review highlighted the following theme. Information and Communications Technologies (ICTs) may Enhance the Coordination of Health, Educational and Social Support - The literature indicates that the use of emerging communications technologies may assist students with chronic health conditions to keep in touch with their schools and peers and may also assist the flow of information between education and health professionals working to support students and their families [3].

The evaluation of the service involved an action research approach to review the service framework and processes. A qualitative research method used to evaluate the service had two data collection phases. Phase One involved focus group meetings with the EAS team (internal stakeholders). Phase Two involved semi-structured interviews with a sample of external key stakeholder groups.

Phase One involved seven meetings with the EAS team. Discussions focused on identifying each stage of service, and identifying the challenges that face the service, and identifying staff responses to those challenges.

Phase Two primary focus involved data collection from the schools accessing the service. Twenty one students with chronic health conditions, their families and their schools and eight health professionals from $\mathrm{RCH}$ were approached to participate in the evaluation.

\subsection{Outcomes}

A total of six recommendations were included in the evaluation report 'Finding a way forward'. Two have significance within the context of this paper. Recommendation 1-That the RCH Education Institute develop a new database to improve reporting and data collection processes; Recommendation 2 -That the $\mathrm{RCH}$ Education Institute develop a framework of processes and procedures to support ongoing improvement in the service.

The final draft of the operational framework has been endorsed by the Board of Directors. Within the framework there are three stages of service, the initial stage, the empowerment stage and the review and close stage. Implementation of the operational framework commenced in March 2008.

Records of school and student contact are stored in a third party database with little flexibility to extract reports. The RCH Education Institute has worked with the RCH Information Technology Department to customize IBA (patient administration system) to address the needs of the service.

An Education Needs Assessment form, (part of the initial stage of service), provides Education Advisors with a formal reporting mechanism that enables the determination of appropriate adjustments to the school's curriculum and environment to support the student's needs. This form is interfaced through the new database system.

Completion of the initial stage of service informs the empowerment stage of service. Education Advisors identify activities used to empower schools. Capacity to clearly identify ICT supports in the previous database system was problematic. The new system clearly identifies ICT supports including laptop provision, virtual classroom usage, online tutoring and video conferencing. 
The review and close stage includes a built in evaluation form for schools. The form is designed to ascertain the quality of service provided, the schools preferred communications method and to identify areas of service improvement.

Implementing new systems of support for students with a chronic health condition and their schools using a project management methodology may improve outcomes for all stakeholders.

\section{Back on Track program (BoT)}

Funded by the Bone Marrow Donor Institute and launched in 2005, the Back on Track program aimed to assist students who are experiencing prolonged absence from school following a diagnosis of cancer and are either in transition from primary to secondary school, or are at upper secondary level. A report to the Bone Marrow Donor Institute and the Institute noted that because it relies on new and emerging technologies for learning exchange and communication, the Program requires a shift in thinking and working for many teachers and clinical staff. Such cultural shifts may be considerable in some settings and changes of this nature take time [5].

Some University of Melbourne pre-service teacher education students began working online with BoT students in 2006. The first online tutors were preparing to become secondary school Information Technology teachers, and they provided online support to BoT students in the subject areas they were qualified in.

In July 2007 researchers from the university and the Institute commenced a three year research project funded by a grant from the Australian Research Council. This project aims to extend the work done in previous years, focusing on perceptions of the students about learning in an online mode, and on the needs of their teachers. The focus in this paper will be on teachers and continuing ICT professional development.

\subsection{Participants}

Student participants in the Back on Track program are at secondary school and are likely to have lengthy absences following diagnosis and treatment for cancer. Teacher participants are teachers from the school of the student. When a student enters the BoT program educational advisors from the Institute meet with teachers from the school and the student's parents to form a student support group. The aim is to clarify the role of the Institute as a conduit for enhancing digital communication between student and teacher, and to explain some of the possible effects a chronic health condition might have on the student's study habits. Other participants are the BoT education program coordinators, one of whom will be the "case manager" for the student, and online tutors who are volunteer pre-service teachers.

\subsection{Method}

BoT students have access to a laptop computer so they can email, chat online or video conference with Institute advisors, teachers and friends. This process 
commences while the students are receiving treatment in hospital, and continues while they are part of BoT. The duration of any student's involvement depends on their health. Students leave the program when they complete their convalescence or rehabilitation and return to school. A conceptual illustration of the lines of communication is given in Fig.1. All electronic communication passes through a server at the Institute. In Fig. 1 the broken lines indicate types of communication that will not be part of the project. Not all data that is generated by participants and automatically recorded on the VLE will be used by the research team. In particular, student communications with either their family or peers will be excluded. All the electronic communication aspects of BoT and other Institute projects are moderated by education advisors in accordance with RCH protocols.

Each BoT student's school is contacted in order to ascertain the infrastructure and support needed by the student from both the Institute and the school. The

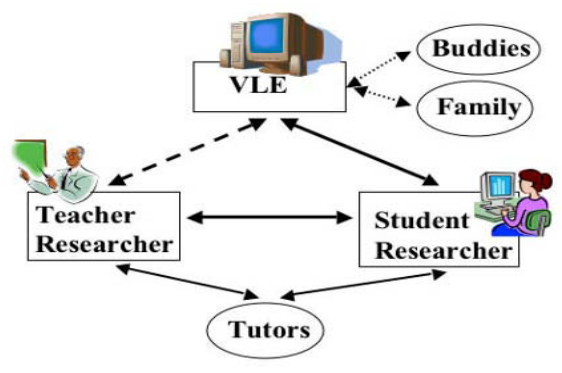
student's learning needs are discussed with the student and one or more teachers. Data for the research is being collected through the traditional ethnographic formats of recording conversations and describing the setting and activities that are part of the project. Some data is collected electronically as the system automatically records users, frequency and length of connection.

Fig. 1. Conceptual view of communications.

This model requires well planned initial and on-going professional development with teacher participants. Reasonable levels of ICT competence and confidence are necessary before a person is employed as an education program coordinator, and the Institute has developed processes for ensuring all staff are involved in on-going refinement of their ICT knowledge and skills that relate to the hardware and software the use as part of their work.

The term "Teacher Researcher" in Fig.1 refers to the classroom teachers who taught the student. Generally secondary students have several teachers they maintain contact with. As students can come from anywhere within a radius of approximately 400 kilometres from Melbourne, the education program coordinators often have to travel long distances to make contact with some teachers and families. Technically the communications model used for this project requires little more than Internet access, and this has reduced the need for advisors and technicians to make multiple visits to schools and student's homes to install equipment.

While many of technical problems have been overcome following the introduction of the new communications model, there remain many problems related to the levels of knowledge and experience that teachers have about using ICT for teaching and learning. Many teachers do not use ICT as an integral component of their everyday classroom practice. Several attempts have been made to conceptualise the connections and interaction between the subject knowledge of teachers, the 
approach to teaching they apply in the classroom, and the use of ICT. In Fig. 2 a model based on Schulman's [6] pedagogical content knowledge of teachers is presented. This conceptual configuration of technological pedagogical content knowledge (TPCK) [7] is being used within the research project. The components of the Mishra \& Koehler model [7] content, pedagogy, technology, and all intersection areas, will be investigated in relation to the perceptions of participating teachers. Teachers will be asked about their previous and current experiences with teaching and learning with ICT in general, and with online teaching in particular. Both staff from the Institute and the researchers are aware of the burden that communicating with a single student who has a chronic illness and no longer attends normal classes can become to teachers not trained in the techniques of online teaching.

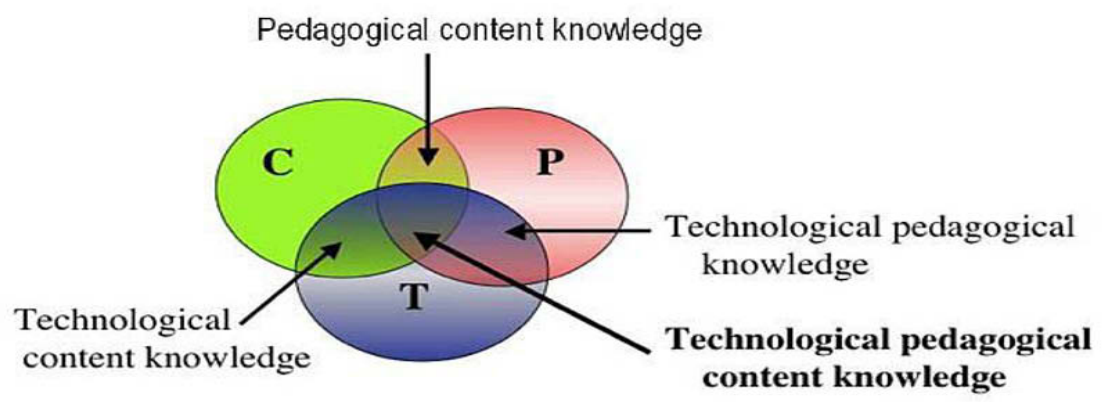

Fig. 2. Technological pedagogical content knowledge (Mishra \& Koehler, 2006).

Both practice and methodology in this project are informed by recent research, conducted in local primary and secondary schools, into classroom uses of ICT for teaching and learning $[8,9]$. A major difference is that in this project students will be asked about their experiences and perceptions of online communication with peers and teachers, especially for learning.

\section{Conclusion}

Although not referred to overtly in this paper, in Australia there is legislation at both federal and state levels that makes it illegal for teachers and schools to discriminate against students who encounter an impediment to their learning. Students with a chronic illness who can be absent from school for months are an example of a group who confront an impediment to their learning. The Education Institute aims to encourage schools to accept their responsibility for students with a chronic health condition through being proactive, and meeting as soon as possible with teachers and administrators from schools of students referred to the Institute.

Making use of the communications affordances of ICT, the Institute has been looking for effective methods, both in terms of education and cost, to connect students who are absent from school as a result of a chronic health condition with their teachers and peers. The projects described in this paper have supplied some answers, but are not in themselves a complete solution. However it is important that 
bodies such as the Institute continue to seek funding to enable new developments in communications technology to be evaluated to help disconnected students re-engage with their education.

\section{References}

1. World Health Organization, WHO 2005 Health topics: Chronic disease. (July 5, 2005); http://www.who.int/topics/chronic_disease/en

2. Department of Education, Science and Training, Information and Communications Technology for Teaching and Learning. Schooling Issues Digest No 2. (July 14, 2007); http://www.dest.gov.au/sectors/school_education/publications_resources/ schooling_issues_digest/schooling_issues_digest_technology.htm

3. L. Campbell, and P. St Ledger, "Finding a way forward..." An evaluation of the Education Advisory Service for the Royal Children's Hospital Education Institute. (Centre for Program Development, University of Melbourne, 2006).

4. Department of Education and Early Childhood Development, Blueprint for government schools (November 28, 2007); http://www.eduweb.vic.gov.au/ edulibrary/public/govrel/reports/blueprint-rpt.pdf

5. L. Campbell, and P. St Leger, On the right track: An evaluation of the Back on Track Pilot program on behalf of the Royal Children's Hospital Education Institute. (Centre for Program Development, University of Melbourne, 2006).

6. L. Schulman, Knowledge and teacher: foundations of the new reform. Harvard Educational Review 56, 1-22 (1987)

7. P. Mishra, and M. Koehler, Technological pedagogical content knowledge: A framework for teacher knowledge. Teachers College Record 108(6), 1017-1054 (2006).

8. A. McDougall, and A. Jones, Theory and history, questions and methodology: current and future issues in research into ICT in education. Technology, Pedagogy and Education. 15 (3): 353-360 (2006).

9 A. Jones, and J. Martin, Monitoring classroom use of ICT in order to improve implementation. In D. Watson, and D. Benzie (eds), Imaging the Future for ICT and Education: IFIP WG 3.1, 3.3 \& 3.5 Joint Conference - CD Proceedings. 176-186. Alesund, Norway: Hogskolen i Alesund/Alesund University College (2006). 